ments of some patients, a twist of the specialist's sound has sometimes rectified a long overlooked twist of the womb. Such tales recall to my memory the boasted achievements of the magician's wand, or the magic touch of the bone-setter's art. I cannot say that this speedy rectification of uterine twists accords with my experience, even when the sound and pessary have been used under the guidance of the respected leaders of the obstetric art. The world has been accustomed to see and to smile at the blindness which often prevents a specialist from finding any other ailment in a consultant than in his favourite organ. Let us hope that it may have been only this form of amiable blindness which afflicted the gentlemen connected with the cases which I have enumerated. In conclusion, there is one thing which I think a specialist should do in such cases : having mentioned the word displacement, he ought also to be particular to explain that, although the ordinary medical attendant may not have said there was displacement, yet that he must have been aware of its existence, as the displacement is generally only one of the symptoms of the disease of the womb afflicting the patient. In disease of the hip-joint, with resulting dislocation on to the ilium, a consulting surgeon would never dismiss the patient under the idea that his ordinary medical attendant had overlooked the dislocation, and that it was simply a case of dislocation of the hip-joint.

\section{ON THE TREATMENT OF STRICTURE OF THE URETHRA.}

BY W. F. TEEVAN, B.A., F.R.C.S., Surgeon to the West London Hospital, etc.

As the report of the paper which I read before the Medical Society was but an abstract, I am happy to supply any information that Mr. Swain may desire. That gentleman states that the French flexible instruments are "very perishable, and, after a few usings, become dangerous." I presume his remarks apply to the English-made instruments, which, like most imitations, are bad. I have tried the French bougies and catheters made and sold in England, and have found them to bear out Mr. Swain's statements regarding them. For many years I have daily used the French instruments, which I import direct from M. Lasserre, 5, Avenue Victoria, Paris; and I can hardly say too much in their praise. They are most durable, and never crack or break. The only care they require is to be kept well oiled, in a warm room. $\mathrm{Mr}$. Swain complains that " in old, long, gristly strictures, they double up and refuse to pass onwards." At the discussion at the Clinical Society, a similar complaint was made by a surgeon regarding these instruments; and I cannot do better than give Mr. Maunder's answer : "With skill and care, the incident referred to would be obviated." If any attempt be made to force onwards the very slender filiform bougies, they will double up; but if they be insinuated with extreme delicacy, and withdrawn a quarter of an inch for every half-inch of progress made, they will rarely fail to penetrate the most desperate strictures. In some cases of hard gristly strictures, I use metallic hougies of the same shape as the elastic bourie olivaire; but, whether I employ metal or elastic bougies, I dilate the patient's urethra up to No. 30 French gauge, considering that No. 25 ought to be the minimum to aspire to. I would here observe that No. 12 English is equal to about No. 20 of the French gauge. Sometimes the narrowness of the meatus externus interferes with dilatation: I accordingly freeze the part and slightly incise it, which procedure affords ample room for the passage onwards of the largest instrument.

Mr. Swain says he "cannot understand how external urethrotomy can be advocated in preference to any other plan of curing stricture." I only perform that operation when, after repeated trials, I fail to pass the smallest instrument. I have consequently to divide the stricture, and work my way into the bladder without any guide. This operation is not Syme's, which requires a staff to be passed through the stricture for a guide; but the old French operation evolved from "la boutonnière". For those limited cases of stricture which can only be dilated to a certain point, or, if dilated, speedily contract again, I recommend the "subcutaneous division" originated by Dr. Henry Dick, to whose writings and those of M. Auguste Mercier I am much indebted, and would refer the readers of the JOURNAL for information.

All statistics published regarding forcible rupture are nearly useless, as they omit to state what was the condition of the urethra immediately before the operation and three years afterwards.

If there be a point in the pathology of sticture on which all surgeons are agreed, it is that the worst of all strictures is the traumaticthat produced by lacerating the mucous membrane; whereas a clean cut into the urethra, as in lithotomy, is not followed by any contrac- tion. Now, if a stricture be split up, we are, by lacerating the mucous membrane, laying the seeds of a traumatic stricture, in addition to the organic one already existing. The cases related by $\mathrm{Mr}$ Timothy Holmes and Mr. W. Stokes show that, if the urethra be examined a few hours after death following forcible rupture, the mucous membrane is found lacerated.

$\mathrm{Mr}$. Swain states that the fatality following forcible rupture must be explained "by its having been used in cases where renal disease or some other unhappy complication rendered any treatment perilous." Now one of the great and inestimable advantages possessed by gradual dilatation, as carried out by the French flexible bougies, is, that the method is absolutely free from danger, no death ever having followed its use anywhere, so far as I can ascertain; whereas forcible rupture would seem to be attended with serious risks to life, and followed by other unfortunate sequences. I know of twenty-one deaths following forcible rupture in the hands of hospital surgeons, plus several more which have occurred at a certain hospital. One hospital surgeon, who had discontinued forcible rupture, told me that, in the last case in which he employed it, the patient was attacked with retention of urine; another hospital surgeon informed me, a few days ago, that in one day he had no less than three cases of bad recurrent strictures after forcible rupture by an eminent surgeon; and a third hospital surgeon showed me a calculus which had formed on the clot after forcible rupture, and said that he had cured by gradual dilatation with the olivary bougie a case which had been twice split within three months, the second operation being followed by such severe hæmorrhage that an instrument had to be tied in for twenty-four hours, which procedure was attended by abscess and fistula in perinceo.

I have but little hope of surgeons agreeing as to which is the best method of treating stricture, until such time as they are all enabled to summon up sufficient moral courage to publish the unsuccessful results attending their operations.

\section{CASES ILLUSTRATING THE OCCURRENCE OF ABNORMAL ERUPTIONS IN SMALL-POX.}

BY FREDERICK POLLARD, M.B.Lond.,

Resident Medical Officer to the St. Pancras and Northern Dispensary.

IN addition to its own specific rash, small-pox is occasionally attended by other eruptions, the occurrence of which may considerably increase the difficulties of diagnosis in the early stages; while in other instances they may have an important bearing on prognosis. These points are severally illustrated by the following two cases.

CASE I. - William M., aged $\mathrm{I}_{7}$, was first seen on the third day of illness. He had then a temperature of 106 deg., no eruption, severe frontal headache, and a thickly coated tongue. He had been sick, but had had no particular back-ache. He had been vaccinated in infancy, and showed two good cicatrices. Next day (the 4th) there was a copious crimson mottled eruption all over the face, body, and arms, occurring chiefly in round spots of the size of a threepenny-piece, in some parts discrete, but mostly running together in mottled patches. The spots were of the colour of measles-eruption, not at all elevated, and fading entirely on pressure. There were also a few slightly elevated papules about the face ; temperature still $106 \mathrm{deg}$. The patient chiefly complained of headache and insomnia. I ordered a dose of chloral at bed-time. Next day (the 5th), the temperature had sunk to roo deg. The crimson rash had entirely disappeared; the variolous papules on the face remaining, and being more elevated and shotty than on the previous day. The patient had slept a good deal, and the headache was better. He was ordered to the Hampstead Hospital, where he has progressed favourably, and is now convalescent.

CASE II. - Jessie T., aged 5, was first seen on the fourth day of illness. On the first and second days, the symptoms had been fever, sickness, and general pains; on the third, the purpurous eruption appeared. When seen (fourth day), she was found to have a temperature of I05 deg., pulse 184 , respirations 84 . There were a large number of purpurous spots from the size of a threepenny-piece downwards on the arms, body, and legs; they were round or oval, with distinct margins, and quite permanent on pressure. There were also two or three marks resembling bruises. In addition to this eruption, there were a few not very characteristic papules about the face ; but the friends were not sure whether these appeared on the third or fourth day, as they had been overlooked, in consequence of the dark blue spots attracting more attention. The child was very restless, continually tossing about, and could not be got to answer questions. There was no evidence of hæmorrhage from any of the mucous membranes, nor of any thoracic mischief. Death occurred the same evening. 
In this case the patient had been vaccinated when an infant, and the arm showed three fairly good cicatrices. This fact does not corroborate a statement made at the Clinical Society a few weeks ago, to the effect that a purpurous eruption in small-pox after vaccination has no unfavourable import ; for here it clearly indicated a very malignant form of disease.

\section{ON THE PAIN OF ATAXY AND ITS RELIEF.}

\section{B y J ULI U A L THA US, M.D., M.R.C.P.,} Physician to the Infirmary for Epilepsy and Paralysis.

THERE are few kinds of pain which equal, and none which surpass, in severity the pain which accompanies certain forms and stages of progressive locomotor ataxy. This pain is short, sharp, and sudden; there is an instant or two of indescribable agony, followed by twenty or thirty seconds, not of rest, but of a kind of drowsy stupor, out of which the patient is roused by another pang, similar to, or even worse than, the first. I have seen strong men, who could bear a great deal without flinching, scream under this infliction; and frequently their cries could be heard at a distance. The pain generally reaches its acme of severity on the third day from the commencement of the attack, and remains of the same character until the eighth day, after which there is a kind of lull. The patient, although utterly wearied and exhausted by suffering and sleeplessness, is, as it were, able to breathe again, as the shocks become less frequent and less severe. Sometimes the pain is quite gone by the tenth day; at other times it goes on in a subdued and sullen manner until a month has passed since its commencement.

Most usually the seat of pain is in the feet and knees, rarely in the hips and back, and quite exceptionally in the upper extremities and the head. Neither swelling nor redness is perceptible during these attacks, which are often set down as being of suppressed gout. They occur, however, in persons who have no gouty habit at all, and do not yield to the remedies which prove most useful in the gouty diathesis. Indeed, the peculiar obstinacy with which the atactic pain defies purely medicinal treatment-even a bold use of hypodermic injections being generally futile-constitutes one of its chief characteristics. That the pain is really part and parcel of ataxy is proved by the concurrence of other symptoms, which the patient often omits to mention on giving an account of his case, but some of which can be invariably elicited by inquiry. Thus, we find that some time previously there has been transitory double vision, or other affections of cerebral nerves that there are sexual debility, and weakness and unsteadiness in walking.

It appears probable that the paroxysmal pains of ataxy are owing to tetanic spasms of the muscular coats of the arteries, caused by irritation of the vaso-motor system of nerves. We have therefore to look for remedies chiefly amongst those agents which we know to possess a powerful influence on the sympathetic. Amongst these, the continuous galvanic current stands facile princeps; and I will now shortly relate a case in which it brought relief, which had for years obstinately resisted all other medication.

J. B., a merchant, aged 35 , married, came under my care in February 1870 . He had for the last six years suffered from periodical attacks of severe pain in some part of the lower extremities, principally the right foot and the left knee. Such an attack generally lasted from two to four weeks, after which the patient was free from it for two or three months, at the expiration of which time a fresh attack would come on. He had never had syphilis. Early in 1864 he suffered from double vision, owing to paralysis of the rectus externus of the right eye. This yielded to treatment in about six weeks, and since then his eyes had been weak, although not suffering from any definite disease. Soon afterwards he noticed that his sexual power was diminished, and that he occasionally had nocturnal emissions, which had not occurred during the previous period of his married life (four years). In August r864 he had the first attack of pain, which was treated with blue pill, opiates, belladonna, and quinine. It lasted about a month, and then vanished. A second attack came in December of the same year, and was treated with colchicum and alkalies. It lasted nearly the same time as the first. When he recovered from the second attack, he felt very weak on his legs, and he had never since then been quite steady, his gait being staggering chiefly in the dark. Attacks now occurred with considerable regularity every two or three months. Some of the later attacks were treated with hypodermic injections of morphia, but with little or no effect. It is true that for fifteen or twenty minutes after the injection the pain was generally not quite so severe as before, but it rapidly resumed its ordinary type. The patient had also tried a great many different kinds of baths; in fact, as he expressed himself, "everything except galvanism," when he came under my care.
He was in bed when I first saw him, racked with pain, which shot periodically through the right instep. I persuaded him, much against his will, to let me use the hypodermic syringe, and injected one-third of a grain of morphia with one-thirty-sixth part of a grain of atropia, near the internal malleolus. This had no further effect, than to make him feel somewhat giddy, and to make the tongue very dry; but it did not relieve the pain at all. The patient being convinced of the uselessness of this proceeding in his case, at my next visit I used, at his urgent request, the continuous galvanic current. This was applied, not loco dolenti, but at the neck, to the course of the cervical sympathetic nerve. After the first application, the patient had about an hour's freedom from pain; after the second, a somewhat longer interval took place; and after the third, the severity of the suffering was considerably diminished. He had altogether ten applications in eight days, after which the pain was entirely relieved; while usually such an attack had lasted a month with him. I now put the patient on a course of nitrate of silver-almost the only medicine which he had not yet taken-for improving the other symptoms of ataxy; and he took this, in doses of from one-sixth to a half grain, for six weeks, with decidedly good effects. He continued quite free from pain for about six months, the next attack occurring in August, having been due in May or June. This attack was not nearly so violent as that in February, and yielded to galvanisation of the sympathetic in the most satisfactory manner. Until now (April 187I) no further attack has taken place; and although it would be rash to assume that the patient will remain altogether free, yet life has in the meantime been rather an enjoyment to him than a burden, and his prospects altogether appear decidedly favourable.

\section{CLINICAL MEMORANDA.}

\section{CALCAREOUS FILM ON THE CORNEA.}

Mr. Dixon, in his remarks on Calcareous Film on the Cornea, notices the fact that, in the cases recorded, though both eyes were affected, the opacities were not, strictly speaking, symmetrical. He seems thus to imply that, in all the recorded cases, both eyes have been affected.

May I be permitted to refer to a case exhibited by me at the Pathological Society during the present session, in which an opacity, in every respect similar to that of the cases exhibited and depicted by Mr. Fairlie Clarke, was present in one eye only? The eye affected was also the subject of extensive intraocular ossification. The case is, I think, interesting as a demonstration that in Mr. Bowman's and Mr. Fairlie Clarke's cases the affection of the two eyes was probably accidental, and that in none of the cases was the disease of the cornea primarily of constitutional origin. W. SPENCER WATSON.

15, Henrietta Street, Cavendish Square.

\section{FACTITIOUS URTICARIA.}

AFTER reading Dr. Broadbent's interesting case of Factitious Urticaria, I cannot refrain from giving my personal experience of that disease. I discovered that I was subject to it six or seven years ago, when attending Dr. Gull's lecture on the subject. I have continued to exhibit it at all times without any change since. Is it not probable that the patient mentioned by Dr. Broadbent may be permanently affected by it? and that the exposure at Christmas had nothing to do with the cause, but led accidentally to the discovery?

Nent Head, Cumberland, May I87r.

$$
\text { GeORGe H. SAvage, M.D.(Lond.) }
$$

\section{SWEATING OF BLOOD.}

A LEADING article in the JOURNAL of last week on the case of Louise Lateau recalls a case to my mind which came under my notice in Honduras some time since. An English proprietor there came some distance to ask my advice for his overseer under the following circumstances. The overseer had been bitten a month previously by a jumping Tomagoff snake, and had been attended by a native snake-doctor at the time of the injury. The overseer recovered from the immediate effects of the bite, although his life was in great danger. A week afterwards he had not recovered from the prostration, and he then began " to sweat blood". His master stated that when he sneezed small spots of blood came out on his face, and that, on making a violent muscular effort with the arm, blood would ooze out on the portion of skin most stretched. The man had been perfectly well before the snake-bite. I prescribed cold baths and iron and strychnine in liberal doses internally. Under this treatment the man recovered in fourteen days. I believe that 